\begin{tabular}{|c|c|c|}
\hline 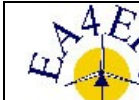 & $\begin{array}{c}\text { European Association for the } \\
\text { Development of Renewable Energies, Environment } \\
\text { and Power Quality (EA4EPQ) }\end{array}$ & $\begin{array}{l}\text { International Conference on Renewable Energies and Power Quality } \\
\text { (ICREPQ'12) } \\
\text { Santiago de Compostela (Spain), 28th to 30th March, } 2012\end{array}$ \\
\hline
\end{tabular}

\title{
Estimation of Power System Harmonics and Interharmonics in the Presence of Aperiodic Components
}

\author{
M.A. Zorrozua ${ }^{1}$, J. Lazaro ${ }^{2}$, J.F. Miñambres ${ }^{1}$, B. Larrea ${ }^{2}$ and M.Sanchez ${ }^{2}$ \\ ${ }^{1}$ Department of Electrical Engineering \\ ${ }^{2}$ Department of Applied Mathematics \\ E.T.S.I., University of the Basque Country (UPV/EHU) \\ Alda. Urquijo s/n, 48013 Bilbao (Spain) \\ Phone/Fax number:+0034 946014056 / +0034 94 6014200, e-mail: miguelangel.zorrozua @ehu.es
}

\begin{abstract}
A new simple method is presented in order to analyze the full harmonic spectrum (harmonic and interharmonic) of a transient signal. The proposed algorithm features a trade-off between accuracy and computational burden. The results obtained show that this method significantly improves the estimation of power system harmonics and interharmonics.
\end{abstract}

\section{Key words}

Harmonic analysis, interharmonics, spectral analysis.

\section{Introduction}

As it is well known, electrical signals (voltages or currents) in actual power systems are not ideal. They can be considered as the sum of a series of different components superimposed over a fundamental component. According to IEC 61000-2-1 and IEC 61000-2-2, their analysis leads to the definition of the following types of components:

- Fundamental component. It is a sinusoidal wave at fundamental frequency $(f)$ of the power system $(f=50 \mathrm{~Hz}$ or $60 \mathrm{~Hz}$ ).

- Harmonic components. They are sinusoidal waves having frequencies $\left(f_{h}\right)$ that are whole multiples of the fundamental frequency. The ratio of the harmonic frequency to the fundamental frequency is called harmonic order $(h)$.

$$
f_{h}=h \cdot f \quad \text { where } h \text { is an integer greater than zero }
$$

- Interharmonic components. IEC-61000-2-1 establishes that "Between the harmonics of the power frequency voltage and current, further frequencies can be observed which are not an integer of the fundamental. They can appear as discrete frequencies or as a wide-band spectrum". Consequently, interharmonic frequency $\left(f_{h}\right)$ is defined as

$$
f_{h} \neq h \cdot f \quad \text { where } h \text { is an integer greater than zero }
$$

By analogy with harmonics, $h$ is called interharmonic order.

- Subharmonic components. They are only a particular case of interharmonic of a frequency $\left(f_{m}\right)$ less than the fundamental frequency.

$$
f_{m}=m \cdot f \quad \text { where } \quad 0<m<1
$$

- Aperiodic components. The constant dc offset and the decaying dc offset are the typical aperiodic components present in an electrical signal.

The presence of harmonic and aperiodic components is very usual in electrical signals, above all during transient periods. In recent years, the interharmonics have increasing importance. Fundamental sources of this last type of components are:

- Arcing loads as those provided by arc furnaces and welding machines. Arc furnaces usually produce significant interharmonics during the initial phase of melting. Welding operations tend to generate a particular spectrum associated with each process.

- Ripple controls such as the metering devices used to regulate the usage of energy at certain times of the day. Ripple control metering is growing in importance nowadays as an attempt to slow global warming and reducing the need for drilling and mining for energy resources.

- Static converters are increasingly used for the integration of distributed power generators, such as photovoltaic systems and speed-variable windmills, into the grid. 
- Variable load electric drives such as motors with variable-torque loading. Also, induction motors can generate interharmonics in association with saturation of the magnetic circuit (slot harmonics), natural asymmetry or rotor misalignment.

\section{Electrical Signals Analysis in the Presence of Interharmonics}

Most instruments used to measure electrical magnitudes in the frequency domain performs properly when only harmonic components are present in the measured signal. So difficulties with interpretation of results arise when other non-harmonic frequencies are present.

According to IEC standards recommendations, several authors have proposed different algorithms for measuring or estimating electrical signal components in the presence of interharmonics.

In this way, among others, the more important methods can be grouped in four basic categories:

- Methods based on Discrete Fourier Transform (DFT) [1]. DFT is very efficient in estimating the harmonic spectrum of a periodic signal. Several DFT based algorithms have been developed to cope with interharmonics present in an electrical signal. Iterative strategies, among other methods, improve the measuring precision with the limitations imposed by the presence of white noise.

- Wavelet packet transform: The method presented in [2] is based on the analysis of the magnitude of harmonic and interharmonic groups instead of targeting individual components. It is also possible to track the time-varying characteristics of harmonic distortion.

- Independent Component Analysis technique (ICA): In [3], the estimation of interharmonics is accomplished with matricial methods specially developed in order to avoid computational costly operations, such as singular value decomposition and eigenvalue decomposition.

Bayesian approach to spectrum analysis: A statistical approach is used in [4] in order to detect the presence of a specific signal waveform and to know how it should be processed to obtain accurate estimates of the signal parameters.

In general, it can be said that these methods increase the number and complexity of the calculations and provide good results when the analyzed signal is stationary and meets the application conditions of each method.

However, if the data window used by the different methods includes data corresponding to transient periods, the proposed algorithms do not provide good results. This is due to that the presence of aperiodic components is a feature not considered in practically all the currently available methods.

\section{New Methodology to Analyze Electrical Signals in the Presence of Interharmonics and Aperiodic Components}

This paper presents a new and simple methodology (Inter-CharmDF) suitable to analyze signals that include transient periods and interharmonics. The method is based on the application of CharmDF (Characteristic Harmonic Digital Filter) [5]. This technique allows to convert a transient signal in a quasi-stationary signal (charm wave) maintaining all the information corresponding to the periodic components (harmonics and interharmonics) of the original transient signal. Consequently, the analysis of charm wave provides information about the components present in the original signal.

Figs. 1 to 5 show different original waves and their corresponding charm waves. According to charmDF methodology, the analysis of the charm wave provides accurate information about the periodic components present in the original signal.

The proposed methodology meets the IEC recommendations and has the following basic features:

- Suitable to analyze signals using a data window that includes only steady state, only transient state or a combination of both.

- Suitable to estimate values corresponding to module and angle of periodic components.

- Application procedure independent of the original wave characteristics and independent of the data window width.

- Results independent of the sampling rate. Logically, only limited by the law of Shannon-Nyquist.

- Flexibility to establish the desired relationship between accuracy and computational burden.

\section{Results}

In order to evaluate the behaviour of the proposed methodology, a set of five case studies are presented. Table I shows the characteristics of the signals used in the different cases. In this table, the symbol $\mathrm{X}$ indicates that the corresponding component type is present in the analyzed signal.

Table I. - Characteristics of the signals

\begin{tabular}{|l|c|c|c|c|c|}
\hline \multicolumn{1}{|c|}{ Components } & $\begin{array}{c}\text { Case } \\
1\end{array}$ & $\begin{array}{c}\text { Case } \\
2\end{array}$ & $\begin{array}{c}\text { Case } \\
3\end{array}$ & $\begin{array}{c}\text { Case } \\
4\end{array}$ & $\begin{array}{c}\text { Case } \\
5\end{array}$ \\
\hline Fundamental & $\mathrm{X}$ & $\mathrm{X}$ & $\mathrm{X}$ & $\mathrm{X}$ & $\mathrm{X}$ \\
\hline Harmonics & $\mathrm{X}$ & $\mathrm{X}$ & $\mathrm{X}$ & $\mathrm{X}$ & $\mathrm{X}$ \\
\hline Interharmonics & $\mathrm{X}$ & $\mathrm{X}$ & $\mathrm{X}$ & $\mathrm{X}$ & $\mathrm{X}$ \\
\hline Subharmonics & $\mathrm{X}$ & $\mathrm{X}$ & $\mathrm{X}$ & $\mathrm{X}$ & $\mathrm{X}$ \\
\hline Constant dc offset & $\mathrm{X}$ & $\mathrm{X}$ & $\mathrm{X}$ & $\mathrm{X}$ & $\mathrm{X}$ \\
\hline Decaying dc offset & & $\mathrm{X}$ & & $\mathrm{X}$ & \\
\hline Multiple decaying dc offset & & & $\mathrm{X}$ & & $\mathrm{X}$ \\
\hline Noise & & & & $\mathrm{X}$ & $\mathrm{X}$ \\
\hline
\end{tabular}


In all cases, the results have been obtained after computing data from ten cycles, as stated in the latest IEC standards, and with a sampling rate of 64 samples/cycle. Similar results have been obtained with other sampling rates.

The cases are presented according to the following structure:

- Mathematical model of the type signal.

- One figure representing both the original wave (blue dotted line) and the corresponding charm wave (green solid line).

- Two tables showing the numeric values of module (first table) and angle (second table). In both, the first column shows the considered components. In second column it can be seen the corresponding exact value and the last columns show the results provided by DFT ( $3^{\text {rd }}$ column $)$ and Inter-CharmDF ( $4^{\text {th }}$ column $)$.

\section{$\underline{\text { Case }-1}$}

Firstly, it is necessary to prove that Inter-CharmDF is able to analyze stationary signals. By this reason, the mathematical model of the signal used in Case- 1 is the following:

$$
\begin{aligned}
y(t)= & A_{0}+\sum_{h=1}^{8} A_{h} \cdot \sin \left(\omega_{h}+\alpha_{h}\right)+A_{m} \cdot \sin \left(\omega_{m}+\alpha_{m}\right)+ \\
& +A_{i 1} \cdot \sin \left(\omega_{i 1}+\alpha_{i 1}\right)+A_{i 2} \cdot \sin \left(\omega_{i 2}+\alpha_{i 2}\right)
\end{aligned}
$$

As an example, this section presents the results corresponding to the original wave shown in Fig.1 and defined in Table II..

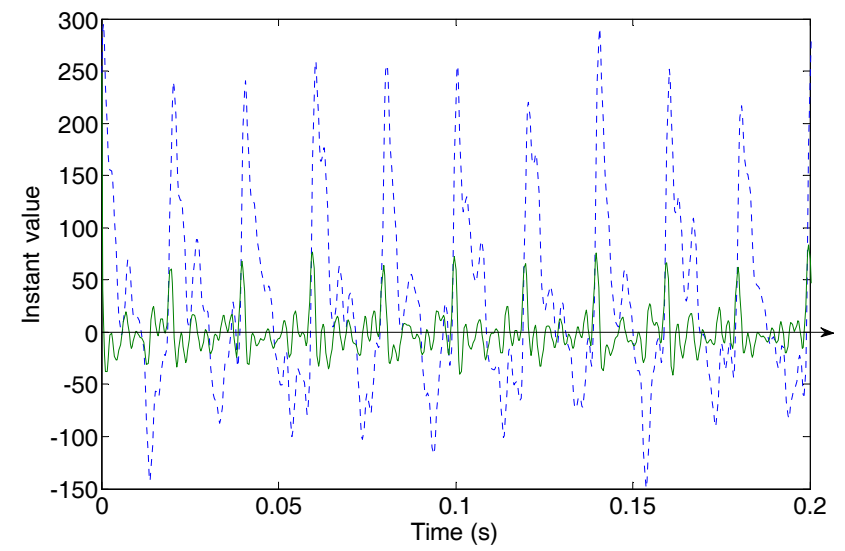

Fig. 1. Case 1: Original wave (blue dotted line) and charm wave (green solid line)

Table II presents the results corresponding to the module estimation and Table III presents the results corresponding to angle estimation.

As it can be seen, although Inter-CharmDF has been developed to analyze signals containing aperiodic components, it provides exact results when it is used to analyze stationary signals. Exact results have been also obtained for signals defined with any other values of the parameters in eq. (1).

Table II. -Case 1: Module estimation results

\begin{tabular}{|l|c|c|c|}
\hline \multicolumn{1}{|c|}{ Component } & $\begin{array}{c}\text { Exact } \\
\text { value }\end{array}$ & DFT & $\begin{array}{c}\text { Inter- } \\
\text { CharmDF }\end{array}$ \\
\hline Fundamental $(50 \mathrm{~Hz})$ & 100 & 100 & 100 \\
\hline $2^{\text {nd }}$ harmonic $(100 \mathrm{~Hz})$ & 50 & 50 & 50 \\
\hline $3^{\text {rd }}$ harmonic $(150 \mathrm{~Hz})$ & 33.33 & 33.33 & 33.33 \\
\hline $4^{\text {th }}$ harmonic $(200 \mathrm{~Hz})$ & 25 & 25 & 25 \\
\hline $5^{\text {th }}$ harmonic $(250 \mathrm{~Hz})$ & 20 & 20 & 20 \\
\hline $6^{\text {th }}$ harmonic $(300 \mathrm{~Hz})$ & 16.67 & 16.67 & 16.67 \\
\hline $7^{\text {th }}$ harmonic $(350 \mathrm{~Hz})$ & 14.28 & 14.28 & 14.28 \\
\hline $8^{\text {th }}$ harmonic $(400 \mathrm{~Hz})$ & 12.50 & 12.50 & 12.50 \\
\hline Subharmonic $(30 \mathrm{~Hz})$ & 10 & 10 & 10 \\
\hline Interharmonic $(115 \mathrm{~Hz})$ & 25 & 25 & 25 \\
\hline Interharmonic $(270 \mathrm{~Hz})$ & 15 & 15 & 15 \\
\hline
\end{tabular}

Table III. -Case 1: Angle estimation results

\begin{tabular}{|l|c|c|c|}
\hline \multicolumn{1}{|c|}{ Component } & $\begin{array}{c}\text { Exact } \\
\text { value }\end{array}$ & DFT & $\begin{array}{c}\text { Inter- } \\
\text { CharmDF }\end{array}$ \\
\hline Fundamental $(50 \mathrm{~Hz})$ & $40^{\circ}$ & $40^{\circ}$ & $40^{\circ}$ \\
\hline $2^{\text {nd }}$ harmonic $(100 \mathrm{~Hz})$ & $65^{\circ}$ & $65^{\circ}$ & $65^{\circ}$ \\
\hline $3^{\text {rd }}$ harmonic $(150 \mathrm{~Hz})$ & $23^{\circ}$ & $23^{\circ}$ & $23^{\circ}$ \\
\hline $4^{\text {th }}$ harmonic $(200 \mathrm{~Hz})$ & $17^{\circ}$ & $17^{\circ}$ & $17^{\circ}$ \\
\hline $5^{\text {th }}$ harmonic $(250 \mathrm{~Hz})$ & $82^{\circ}$ & $82^{\circ}$ & $82^{\circ}$ \\
\hline $6^{\text {th }}$ harmonic $(300 \mathrm{~Hz})$ & $58^{\circ}$ & $58^{\circ}$ & $58^{\circ}$ \\
\hline $7^{\text {th }}$ harmonic $(350 \mathrm{~Hz})$ & $37^{\circ}$ & $37^{\circ}$ & $37^{\circ}$ \\
\hline $8^{\text {th }}$ harmonic $(400 \mathrm{~Hz})$ & $24^{\circ}$ & $24^{\circ}$ & $24^{\circ}$ \\
\hline Subharmonic $(30 \mathrm{~Hz})$ & $70^{\circ}$ & $70^{\circ}$ & $70^{\circ}$ \\
\hline Interharmonic $(115 \mathrm{~Hz})$ & $30^{\circ}$ & $30^{\circ}$ & $30^{\circ}$ \\
\hline Interharmonic $(270 \mathrm{~Hz})$ & $51^{\circ}$ & $51^{\circ}$ & $51^{\circ}$ \\
\hline
\end{tabular}

$\underline{\text { Case }-2}$

The aim of this case study is to evaluate the behaviour of Inter-CharmDF in the presence of a decaying dc offset. According to Table I, eq. (2) defines the mathematical model of the test signals.

$$
\begin{aligned}
y(t)= & A_{0}+B \cdot e^{-t / \tau}+\sum_{h=1}^{8} A_{h} \cdot \sin \left(\omega_{h}+\alpha_{h}\right)+ \\
& +A_{m} \cdot \sin \left(\omega_{m}+\alpha_{m}\right)+A_{i} \cdot \sin \left(\omega_{i}+\alpha_{i}\right)
\end{aligned}
$$

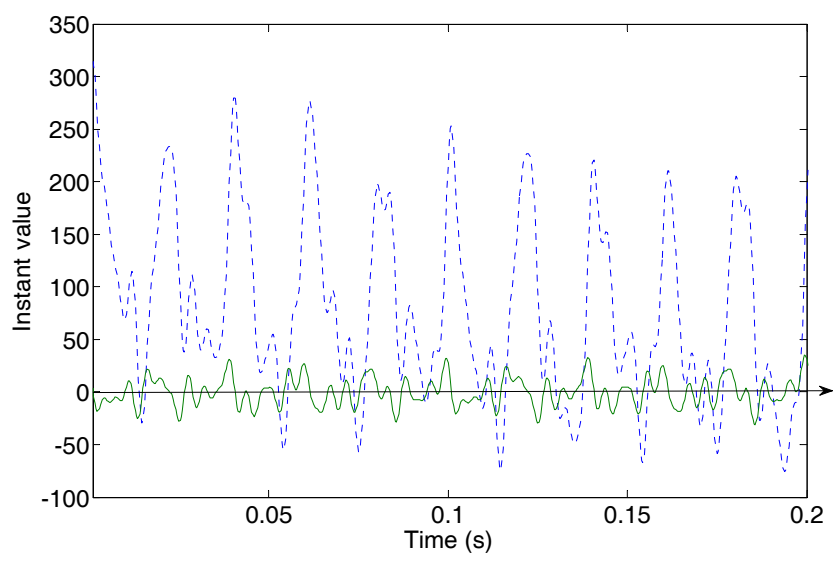

Fig. 2. Case2: Original wave (blue dotted line) and charm wave (green solid line) 
The original wave shown in Fig. 2 corresponds to a decaying dc offset with an initial amplitude of 100 (equal to the amplitude of fundamental component) and a time constant of $125 \mathrm{~ms}$ ( 6.25 cycles $)$. The values of the rest of components and the results can be seen in Tables IV and $\mathrm{V}$.

The components with amplitude equal to zero are not present in the signal. They have been included in Table IV in order to illustrate the capability of Inter-CharmDF to detect components non-present in the analyzed signal.

Similar results have been obtained for signals defined according to eq. (2) and different values of parameters.

Table IV. Case 2: Module estimation results

\begin{tabular}{|l|c|c|c|}
\hline \multicolumn{1}{|c|}{ Component } & $\begin{array}{c}\text { Exact } \\
\text { value }\end{array}$ & DFT & $\begin{array}{c}\text { Inter- } \\
\text { CharmDF }\end{array}$ \\
\hline Fundamental $(50 \mathrm{~Hz})$ & 100 & 101.792 & 100.048 \\
\hline $2^{\text {nd }}$ harmonic $(100 \mathrm{~Hz})$ & 50 & 50.929 & 50.012 \\
\hline $3^{\text {rd }}$ harmonic $(150 \mathrm{~Hz})$ & 0 & 0.851 & 0.007 \\
\hline $4^{\text {th }}$ harmonic $(200 \mathrm{~Hz})$ & 0 & 0.640 & 0.004 \\
\hline $5^{\text {th }}$ harmonic $(250 \mathrm{~Hz})$ & 15 & 15.423 & 15.002 \\
\hline $6^{\text {th }}$ harmonic $(300 \mathrm{~Hz})$ & 0 & 0.430 & 0.001 \\
\hline $7^{\text {th }}$ harmonic $(350 \mathrm{~Hz})$ & 0 & 0.370 & 0.001 \\
\hline $8^{\text {th }}$ harmonic $(400 \mathrm{~Hz})$ & 0 & 0.326 & 0.001 \\
\hline $10^{\text {th }}$ harmonic $(500 \mathrm{~Hz})$ & 0 & 0.265 & 0.000 \\
\hline Subharmonic $(35 \mathrm{~Hz})$ & 20 & 23.624 & 19.995 \\
\hline Interharmonic $(180 \mathrm{~Hz})$ & 30 & 30.666 & 30.002 \\
\hline Subharmonic $(45 \mathrm{~Hz})$ & 0 & 2.826 & 0.079 \\
\hline Interharmonic $(235 \mathrm{~Hz})$ & 0 & 0.452 & 0.002 \\
\hline
\end{tabular}

Table V. Case 2: Angle estimation results

\begin{tabular}{|l|c|c|c|}
\hline \multicolumn{1}{|c|}{ Component } & $\begin{array}{c}\text { Exact } \\
\text { value }\end{array}$ & DFT & $\begin{array}{c}\text { Inter- } \\
\text { CharmDF }\end{array}$ \\
\hline Fundamental $(50 \mathrm{~Hz})$ & $50^{\circ}$ & $48.975^{\circ}$ & $50.024^{\circ}$ \\
\hline $2^{\text {nd }}$ harmonic $(100 \mathrm{~Hz})$ & $38^{\circ}$ & $37.250^{\circ}$ & $38.014^{\circ}$ \\
\hline $5^{\text {th }}$ harmonic $(250 \mathrm{~Hz})$ & $62^{\circ}$ & $60.582^{\circ}$ & $62.004^{\circ}$ \\
\hline Subharmonic $(35 \mathrm{~Hz})$ & $23^{\circ}$ & $20.119^{\circ}$ & $23.352^{\circ}$ \\
\hline Interharmonic $(180 \mathrm{~Hz})$ & $31^{\circ}$ & $30.536^{\circ}$ & $31.008^{\circ}$ \\
\hline
\end{tabular}

\section{$\underline{\text { Case }-3}$}

In order to test Inter-CharmDF under extreme conditions, Case-3 uses test signals including the presence of multiple decaying dc offsets. The mathematical model of these signals is defined in eq. (3).

$$
\begin{aligned}
y(t)= & A_{0}+B_{1} \cdot e^{-t / \tau_{1}}+B_{2} \cdot e^{-t / \tau_{2}}+ \\
& +\sum_{h=1}^{8} A_{h} \cdot \sin \left(\omega_{h}+\alpha_{h}\right)+A_{m} \cdot \sin \left(\omega_{m}+\alpha_{m}\right)+ \\
& +A_{i 1} \cdot \sin \left(\omega_{i 1}+\alpha_{i 1}\right)+A_{i 2} \cdot \sin \left(\omega_{i 2}+\alpha_{i 2}\right)
\end{aligned}
$$

The signal used to illustrate this section is shown in Fig.3. It is composed by the components defined in Tables VI and VII and two decaying dc offsets.
According to nomenclature used in eq. (3), the corresponding values are $B_{1}=100, B_{2}=75$, $\tau_{1}=200 \mathrm{~ms}$ and $\tau_{2}=100 \mathrm{~ms}$

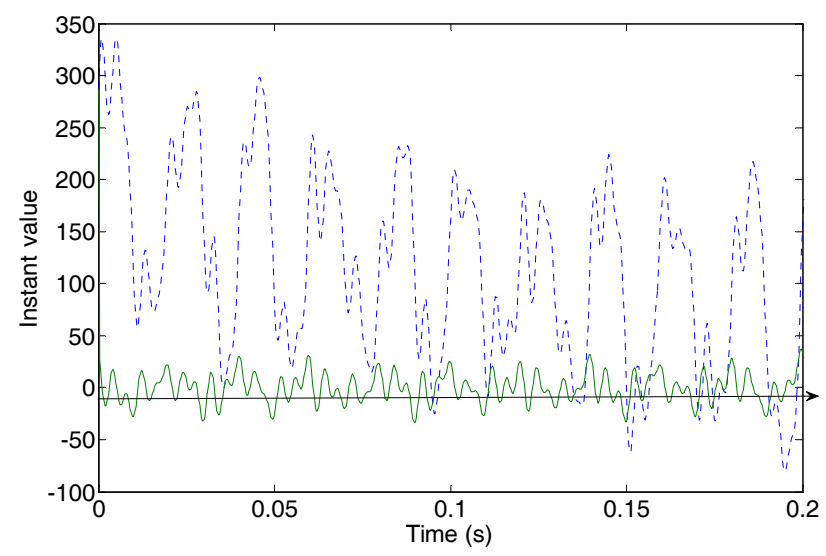

Fig. 3. Case 3: Original wave (blue dotted line) and charm wave (green solid line)

Table VI. Case 3: Module estimation results

\begin{tabular}{|l|c|c|c|}
\hline \multicolumn{1}{|c|}{ Component } & $\begin{array}{c}\text { Exact } \\
\text { value }\end{array}$ & DFT & $\begin{array}{c}\text { Inter- } \\
\text { CharmDF }\end{array}$ \\
\hline Fundamental $(50 \mathrm{~Hz})$ & 100 & 104.076 & 100.009 \\
\hline $2^{\text {nd }}$ harmonic $(100 \mathrm{~Hz})$ & 0 & 2.044 & 0.024 \\
\hline $3^{\text {rd }}$ harmonic $(150 \mathrm{~Hz})$ & 37 & 37.688 & 37.010 \\
\hline $4^{\text {th }}$ harmonic $(200 \mathrm{~Hz})$ & 0 & 1.027 & 0.006 \\
\hline $5^{\text {th }}$ harmonic $(250 \mathrm{~Hz})$ & 23 & 23.823 & 23.001 \\
\hline $6^{\text {th }}$ harmonic $(300 \mathrm{~Hz})$ & 0 & 0.690 & 0.002 \\
\hline $7^{\text {th }}$ harmonic $(350 \mathrm{~Hz})$ & 0 & 0.595 & 0.002 \\
\hline $8^{\text {th }}$ harmonic $(400 \mathrm{~Hz})$ & 0 & 0.523 & 0.001 \\
\hline $9^{\text {th }}$ harmonic $(450 \mathrm{~Hz})$ & 0 & 0.469 & 0.001 \\
\hline Subharmonic $(45 \mathrm{~Hz})$ & 20 & 24.333 & 20.044 \\
\hline Interharmonic $(70 \mathrm{~Hz})$ & 30 & 32.403 & 30.032 \\
\hline Interharmonic $(215 \mathrm{~Hz})$ & 12 & 12.638 & 12.004 \\
\hline Subharmonic $(40 \mathrm{~Hz})$ & 0 & 5.100 & 0.152 \\
\hline Interharmonic $(165 \mathrm{~Hz})$ & 0 & 1.242 & 0.009 \\
\hline
\end{tabular}

Table VII. Case 3: Angle estimation results

\begin{tabular}{|l|c|c|c|}
\hline \multicolumn{1}{|c|}{ Component } & $\begin{array}{c}\text { Exact } \\
\text { value }\end{array}$ & DFT & $\begin{array}{c}\text { Inter- } \\
\text { CharmDF }\end{array}$ \\
\hline Fundamental $(50 \mathrm{~Hz})$ & $7^{\circ}$ & $6.889^{\circ}$ & $7.055^{\circ}$ \\
\hline $3^{\text {rd }}$ harmonic $(150 \mathrm{~Hz})$ & $71^{\circ}$ & $69.164^{\circ}$ & $71.005^{\circ}$ \\
\hline $5^{\text {th }}$ harmonic $(250 \mathrm{~Hz})$ & $18^{\circ}$ & $17.873^{\circ}$ & $18.009^{\circ}$ \\
\hline Subharmonic $(45 \mathrm{~Hz})$ & $23^{\circ}$ & $19.532^{\circ}$ & $23.321^{\circ}$ \\
\hline Interharmonic $(70 \mathrm{~Hz})$ & $41^{\circ}$ & $37.961^{\circ}$ & $41.073^{\circ}$ \\
\hline Interharmonic $(215 \mathrm{~Hz})$ & $63^{\circ}$ & $59.646^{\circ}$ & $63.011^{\circ}$ \\
\hline
\end{tabular}

\section{$\underline{\text { Case }-4}$}

The proposed methodology has been also tested with noisy signals. The type of signal used is defined by eq. (4).

$$
\begin{aligned}
y(t)= & A_{0}+B \cdot e^{-t / \tau}+\sum_{h=1}^{8} A_{h} \cdot \sin \left(\omega_{h}+\alpha_{h}\right)+ \\
& +A_{m} \cdot \sin \left(\omega_{m}+\alpha_{m}\right)+A_{i} \cdot \sin \left(\omega_{i}+\alpha_{i}\right)+\operatorname{noise}(t)
\end{aligned}
$$


Fig. 4 and Tables VIII and IX correspond to a noisy signal that includes a random noise (within a range of $\pm 2.5 \%$ of fundamental component amplitude) and a decaying dc offset (with an initial amplitude of 100 and a time constant of $60 \mathrm{~ms})$.

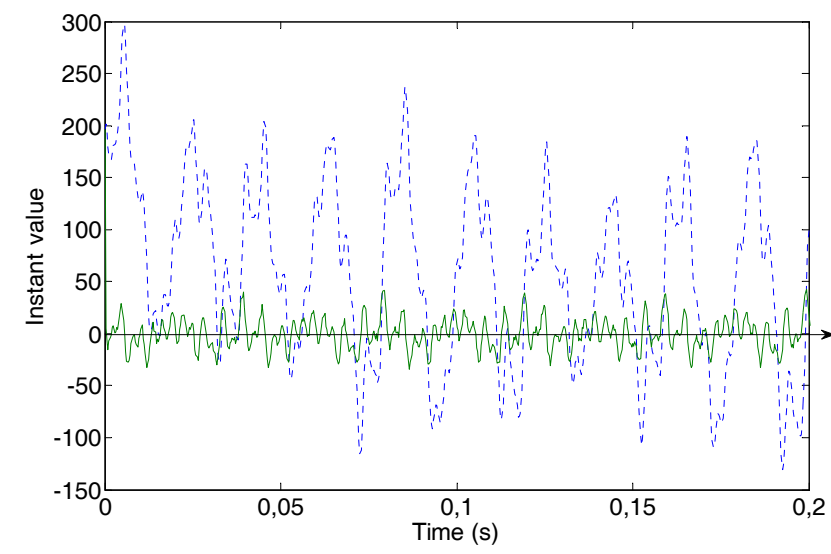

Fig. 4. Case 4: Original wave (blue dotted line) and charm wave (green solid line)

Table VIII. Case 4: Module estimation results

\begin{tabular}{|l|c|c|c|}
\hline \multicolumn{1}{|c|}{ Component } & $\begin{array}{c}\text { Exact } \\
\text { value }\end{array}$ & DFT & $\begin{array}{c}\text { Inter- } \\
\text { CharmDF }\end{array}$ \\
\hline Fundamental $(50 \mathrm{~Hz})$ & 100 & 103.138 & 100.119 \\
\hline $2^{\text {nd }}$ harmonic $(100 \mathrm{~Hz})$ & 0 & 1.415 & 0.142 \\
\hline $3^{\text {rd }}$ harmonic $(150 \mathrm{~Hz})$ & 0 & 1.041 & 0.036 \\
\hline $4^{\text {th }}$ harmonic $(200 \mathrm{~Hz})$ & 28 & 28.188 & 27.977 \\
\hline $5^{\text {th }}$ harmonic $(250 \mathrm{~Hz})$ & 0 & 0.737 & 0.188 \\
\hline $6^{\text {th }}$ harmonic $(300 \mathrm{~Hz})$ & 0 & 0.527 & 0.078 \\
\hline $7^{\text {th }}$ harmonic $(350 \mathrm{~Hz})$ & 18 & 17.876 & 17.911 \\
\hline $8^{\text {th }}$ harmonic $(400 \mathrm{~Hz})$ & 0 & 0.358 & 0.033 \\
\hline $10^{\text {th }}$ harmonic $(500 \mathrm{~Hz})$ & 0 & 0.231 & 0.097 \\
\hline Subharmonic $(40 \mathrm{~Hz})$ & 30 & 32.980 & 29.819 \\
\hline Interharmonic $(175 \mathrm{~Hz})$ & 25 & 25.588 & 25.092 \\
\hline Subharmonic $(45 \mathrm{~Hz})$ & 0 & 3.298 & 0.159 \\
\hline Interharmonic $(235 \mathrm{~Hz})$ & 0 & 0.688 & 0.102 \\
\hline
\end{tabular}

Table IX. Case 4: Angle estimation results

\begin{tabular}{|l|c|c|c|}
\hline \multicolumn{1}{|c|}{ Component } & $\begin{array}{c}\text { Exact } \\
\text { value }\end{array}$ & DFT & $\begin{array}{c}\text { Inter- } \\
\text { CharmDF }\end{array}$ \\
\hline Fundamental $(50 \mathrm{~Hz})$ & $10^{\circ}$ & $9.812^{\circ}$ & $10.024^{\circ}$ \\
\hline $4^{\text {th }}$ harmonic $(200 \mathrm{~Hz})$ & $86^{\circ}$ & $84.542^{\circ}$ & $86.043^{\circ}$ \\
\hline $7^{\text {th }}$ harmonic $(350 \mathrm{~Hz})$ & $115^{\circ}$ & $113.484^{\circ}$ & $114.899^{\circ}$ \\
\hline Subharmonic $(40 \mathrm{~Hz})$ & $-34^{\circ}$ & $-29.635^{\circ}$ & $-33.497^{\circ}$ \\
\hline Interharmonic $(175 \mathrm{~Hz})$ & $66^{\circ}$ & $64.423^{\circ}$ & $66.048^{\circ}$ \\
\hline
\end{tabular}

Similar results have been obtained for signals defined according to eq. (4) and different values of parameters.

\section{$\underline{\text { Case }-5}$}

From the cases carried out by the authors, this paper finally presents the case study corresponding to the analysis of signals containing the type of components shown in last column of Table I. In addition to the fundamental component, this original signal includes harmonics, subharmonics, interharmonics, constant dc offset, two decaying dc offsets and noise.
The mathematical model of case- 5 signal is defined in eq. (5).

$$
\begin{aligned}
y(t)= & A_{0}+B_{1} \cdot e^{-t / \tau_{1}}+B_{2} \cdot e^{-t / \tau_{2}}+\sum_{h=1}^{8} A_{h} \cdot \sin \left(\omega_{h}+\alpha_{h}\right)+ \\
& +A_{m 1} \cdot \sin \left(\omega_{m 1}+\alpha_{m 1}\right)+A_{m 2} \cdot \sin \left(\omega_{m 2}+\alpha_{m 2}\right)+ \\
& +A_{i} \cdot \sin \left(\omega_{i}+\alpha_{i}\right)+\text { noise }(t)
\end{aligned}
$$

The original signal used to illustrate the example presented in this section has the following parameter values: $B_{1}=100, B_{2}=85, \quad \tau_{1}=50 \mathrm{~ms} \quad$ and $\tau_{2}=180 \mathrm{~ms}$.

The values corresponding to the harmonics, interharmonics and subharmonics components can be seen in the second column of Tables X and XI.

The original signal also includes a random noise within a range $\pm 5 \%$ of fundamental component amplitude.

The shape corresponding to this original noisy signal and to its charm wave is shown in Fig.5.

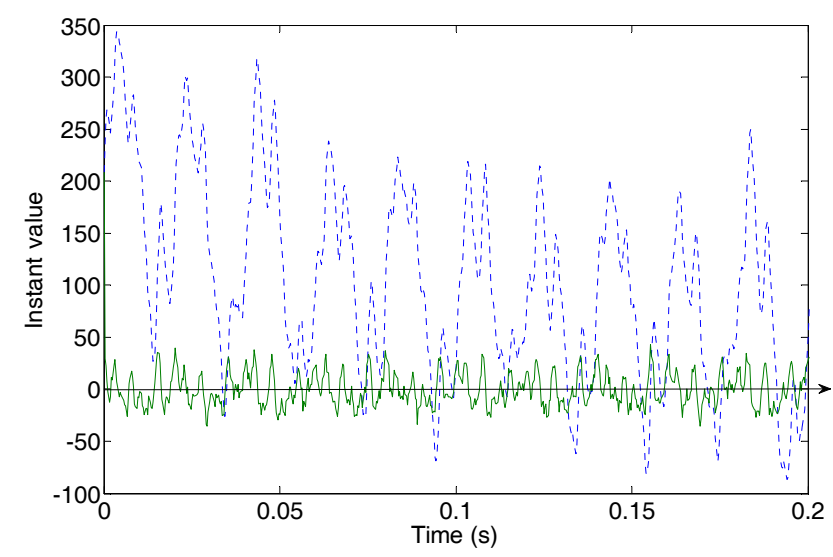

Fig. 5. Case 5: Original wave (blue dotted line) and charm wave (green solid line)

As in previous cases, Table $\mathrm{X}$ and $\mathrm{XI}$ show the results corresponding to the amplitude estimation (Table $\mathrm{X}$ ) and to the angle estimation (Table XI).

Table X. Case 5: Module estimation results

\begin{tabular}{|l|c|c|c|}
\hline \multicolumn{1}{|c|}{ Component } & $\begin{array}{c}\text { Exact } \\
\text { value }\end{array}$ & DFT & $\begin{array}{c}\text { Inter- } \\
\text { CharmDF }\end{array}$ \\
\hline Fundamental $(50 \mathrm{~Hz})$ & 100 & 104.926 & 99.964 \\
\hline $2^{\text {nd }}$ harmonic $(100 \mathrm{~Hz})$ & 0 & 2.679 & 0.195 \\
\hline $3^{\text {rd }}$ harmonic $(150 \mathrm{~Hz})$ & 35 & 35.522 & 35.148 \\
\hline $4^{\text {th }}$ harmonic $(200 \mathrm{~Hz})$ & 0 & 1.149 & 0.164 \\
\hline $5^{\text {th }}$ harmonic $(250 \mathrm{~Hz})$ & 22 & 22.664 & 21.961 \\
\hline $6^{\text {th }}$ harmonic $(300 \mathrm{~Hz})$ & 0 & 1.121 & 0.291 \\
\hline $7^{\text {th }}$ harmonic $(350 \mathrm{~Hz})$ & 0 & 0.509 & 0.245 \\
\hline $8^{\text {th }}$ harmonic $(400 \mathrm{~Hz})$ & 13 & 13.269 & 12.885 \\
\hline Subharmonic $(30 \mathrm{~Hz})$ & 18 & 22.768 & 17.172 \\
\hline Subharmonic $(45 \mathrm{~Hz})$ & 15 & 19.498 & 14.924 \\
\hline Interharmonic $(185 \mathrm{~Hz})$ & 22 & 22.412 & 21.937 \\
\hline Subharmonic $(40 \mathrm{~Hz})$ & 0 & 6.290 & 0.213 \\
\hline Interharmonic $(135 \mathrm{~Hz})$ & 0 & 1.919 & 0.107 \\
\hline
\end{tabular}


Table XI. Case 5: Angle estimation results

\begin{tabular}{|l|c|c|c|}
\hline \multicolumn{1}{|c|}{ Component } & $\begin{array}{c}\text { Exact } \\
\text { value }\end{array}$ & DFT & $\begin{array}{c}\text { Inter- } \\
\text { CharmDF }\end{array}$ \\
\hline Fundamental $(50 \mathrm{~Hz})$ & $0^{\circ}$ & $0.193^{\circ}$ & $0.063^{\circ}$ \\
\hline $3^{\text {rd }}$ harmonic $(150 \mathrm{~Hz})$ & $-70^{\circ}$ & $-67.244^{\circ}$ & $-69.869^{\circ}$ \\
\hline $5^{\text {th }}$ harmonic $(250 \mathrm{~Hz})$ & $60^{\circ}$ & $58.698^{\circ}$ & $60.537^{\circ}$ \\
\hline $8^{\text {th }}$ harmonic $(400 \mathrm{~Hz})$ & $-27^{\circ}$ & $-25.866^{\circ}$ & $-27.988^{\circ}$ \\
\hline Subharmonic $(30 \mathrm{~Hz})$ & $-55^{\circ}$ & $-37.770^{\circ}$ & $-55.053^{\circ}$ \\
\hline Subharmonic $(45 \mathrm{~Hz})$ & $41^{\circ}$ & $31.697^{\circ}$ & $42.079^{\circ}$ \\
\hline Interharmonic $(185 \mathrm{~Hz})$ & $82^{\circ}$ & $78.181^{\circ}$ & $81.445^{\circ}$ \\
\hline
\end{tabular}

Similar results have been obtained for signals defined according to eq. (5) and different values of parameters.

In short, the analysis of the results obtained in the five cases points out that:

- Inter-CharmDF allows to accurately estimate the module and angle of the fundamental, harmonic, interharmonic and subharmonic components present in electrical signals containing aperiodic components.

- The presence of a constant dc offset does not affect to the Inter-CharmDF methodology. Any value of this parameter produces the same results which are shown in Tables II to XI. By this reason, the constant dc offset value has not been defined in the different cases presented in this paper.

- In addition, Inter-CharmDF is able to detect with high reliability the non presence of periodic components.

- The proposed methodology is based on the definition of a quasi-stationary signal (charm wave) which maintains information about all the periodic components present in the original signal. By this reason, any methodology valid to analyze stationary signals can be used to analyze the charm wave and obtain information about the periodic components present in the original signal.

\section{Conclusions}

The methodology INTER-CharmDF is suitable to analyze transient electrical signals in the presence of harmonics and interharmonics.
The results prove that Inter-CharmDF is able to estimate accurately any periodic component (fundamental, harmonics, interharmonics and subharmonic) present in the analyzed signal, even when the signal includes aperiodic components and/or noise.

In addition, they show that it is also able to detect with high reliability the non-presence of any periodic component.

Inter-CharmDF is based on the definition of a quasistationary signal (charm wave). By this reason, this methodology improves any currently method applicable to stationary signals as it expands its field of application to transient signals.

\section{Acknowledgement}

The research work presented in this paper is part of the Research Project "Repercusiones de interarmónicos en el comportamiento de los sistemas de protección de redes eléctricas", sponsored by the University of the Basque Country (UPV/EHU-Ref.EHU08/47).

\section{References}

[1] Q. Zhang, H. Liu, H. Chen, Q. Li and Z. Zhang "A precise an adaptive algorithm for interharmonics measurement based on iterative DFT", IEEE Transactions on Power Delivery, Vol. 23, no. 4, pp. 1728-1735, October 2008

[2] R.I. Diego, "Global method for time-frequency analysis of harmonic distortion in power systems using the wavelet packet transform", Electric Power Systems Research, Vol. 79, no. 8, pp. 1226-1239, August 2009

[3] Z. Liquan and J. YAnfei C, "Interharmonic estimation based on complex valued independent component analysis", in Proc. WCNIS 2010, Vol. 1, pp. 248-251, June 2010

[4] G.A. Kyriazia, "A simple algorithm for Bayesian signal analysis with applications to metrology", IEEE Transactions on Instrumentation and Measurement, Vol. 60, no. 7, pp. 2314-2319, , July 2011

[5] J. Lázaro, J.F. Miñambres, M.A. Zorrozua, B. Larrea, M. Sánchez and I. Antiza "New quick-convergence invariant digital filter for phasor estimation", Electric Power Systems Research, Vol. 79, no. 5, pp. 705-713, May 2009 